\title{
A Structured Approach to Defect Data Management for Improving DFM Implementation in Aerospace Manufacturing
}

\section{Mohammed El Souri, James Gao, Oladele Owodunni}

Faculty of Engineering and Science,

University of Greenwich,

Central Avenue,

Chatham Maritime,

ME4 4TB,

United Kingdom

\section{Clive Simmonds, Nick Martin}

Electronic Systems,

BAE Systems,

Rochester,

Kent,

ME1 2XX

United Kingdom

\begin{abstract}
The aim of adopting Product Lifecycle Management in a highly product centric knowledge environment is to reduce product development time and costs whilst improving quality through integrating people, processes, resources and information effectively. In the aerospace industry, most products and systems are manufactured, delivered to customers and serviced over an extensively long time, typically 20 years or more. This results in the build-up of large amounts of dispersed data and information related to defects throughout the different product's lifecycle stages, hence inhibiting the ability to make effective use of defect data to improve design for manufacturing (DFM) implementation. There have been very limited research efforts aiming to overcome these challenges in the low volume high value aerospace manufacturing context. This paper presents the findings of an extensive industrial investigation carried out at BAE Systems (Rochester, UK) to identify the gaps and requirements in the industrial practice and proposes the need for a structured approach to defect data management in order to establish the systematic link between the defects, engineering data, and related issues within PLM System context.
\end{abstract}

Keywords: knowledge management; product lifecycle management; design for manufacturing

Reference to this paper should be made as follows: El Souri, M., Gao, J., Owodunni, O., Simmonds, C., and Martin, N. (2017) 'A Structured Approach to Defect Data Management for Improving DFM Implementation in Aerospace Manufacturing', Int. J. Product Lifecycle Management, Vol. X, No, Y, xxxx

Biographical notes: Mohammed El Souri is currently undertaking a $\mathrm{PhD}$ research project funded by ESPRC in collaboration with BAE Systems looking at improving the management of Design for Manufacturing (DFM) knowledge 
A Structured Approach to Defect Data Management for Improving DFM Implementation in Aerospace Manufacturing

in the systems engineering context for the Aerospace Industry. He previously obtained his MSc in Integrated Product Design and BSc in Industrial Design from the University of Brunel and worked as an Industrial Designer and Mechanical Design Engineer for a variety of industries. His research sheds light on new aspects critical to address some of the current industrial challenges in the field of Knowledge Management, Systems Engineering and Design for Manufacturing in High Value Manufacturing context.

James Gao is the Medway Chair of Manufacturing Engineering, and leads the Design, Manufacturing and Innovative Products Theme, Faculty of Engineering and Science, University of Greenwich. Prior to his current position, he was a lecturer/senior lecturer at Cranfield University from 1993-2006. Prof Gao is a Fellow of the Institution of Mechanical Engineers, Associate Editor of the Proceedings of IMechE Part B - Journal of Engineering Manufacture, and a member of the editorial board of several international journals. He obtained his BSc in mechanical engineering in 1984 from Dalian Institute of Technology (China), MSc and PhD from the University of Manchester Institute of Science and Technology (UK) in 1987 and 1989 respectively. He has over 230 publications in international journals and conferences, and directed a large number of research projects in the areas of Knowledge Management, Intelligent Manufacturing, Collaborative Product Development, Computer Aided Design and Manufacturing, and Product Lifecycle Management.

Oladele Owodunni is currently a Senior lecturer in the Department of Applied Engineering and Management at the University of Greenwich. His research area is in Mechanical Design and Manufacturing, particularly the computer implementable support aspect for these activities like Computer Aided Design (CAD)/ Computer Aided Manufacturing (CAM), and Digital Manufacturing. Currently Owodunni is focusing on Sustainable Manufacturing. He obtained his $\mathrm{PhD}$ from the University of Manchester Institute of Science and Technology (UK) in 2001 and was a Research Associate there till 2008.

Clive Simmonds is currently the Chief Engineer of Operations for BAE Systems, Rochester. He is the materials and processes specialist for design for manufacture, assembly and test of complex electro mechanical and optical systems. Clive has almost 30 years' experience in the Aerospace industry and is currently an active contributor to numerous high profile industrial forums including ADS, TechUK, NPL, and BAE Systems, continuously adding to the UK and EU body of knowledge. Clive leads collaborative reviews across a global supplier base for BAE Systems and has previously been both Manufacturing Director and the Manufacturing Engineering Manager responsible for ensuring Rochester's end products and systems meet the right schedule, cost and quality requirements. $\mathrm{He}$ is also a Lean Six Sigma Black Belt and continues to support the company's drive for Operational Excellence and Zero Defect Approach.

Nick Martin is currently the Innovation and Growth Director at BAE Systems, Rochester. His role involves creating state-of-the-art technology strategies on new and existing avionic systems. He is an engineering fellow and is continuously leading collaborations between academia and industries in the development of innovative cutting edge technologies. Previously, Nick Martin has been the Chief Technologist at BAE Systems with decades of experience in Research and Development and New Product Development activities. 


\section{A Structured Approach to Defect Data Management for Improving DFM Implementation in Aerospace Manufacturing}

\section{$1 \quad$ Introduction}

For the past two decades, Product Lifecycle Management (PLM) systems have been rapidly implemented in the manufacturing industry for managing all aspects of information related to a product's life - from its initial creation, development and manufacturing through to its maintenance and end of life [1]. PLM systems remain primarily the crucial resource used for organising and storing product-centric information created and communicated across the teams involved in the project lifecycle to deliver complex projects [2]. In large scale manufacturing, however, the management of 'big' complex datasets in PLM systems to enable effective Design for Manufacturing (DFM) implementation remains a significant challenge that needs to be addressed today [3].

Although this challenge is widely discussed in literature related to Extended Enterprises [4], Knowledge Management (KM), Collaboration Technology [5], Industry 4.0 [6], and Concurrent Engineering [7], most of the approaches proposed for managing large amounts of different types of data for engineering implementation remain very much top down approaches and mostly attempt to improve the understanding of the subject area; whilst very rarely aim to develop solutions that address how defect data can be used to enable more effective DFM implementations within low volume high value complex industrial context. Nevertheless, a more effective, responsive DFM approach to be achieved based on real-life defect data can play a significant role in enabling engineers to create closedloop design rationales developed from knowledge of manufacturing processes and is critical in reducing development time and costs whilst improving quality [8]. This research adopts this approach by considering how the defect data captured and stored in manufacturing can be used for facilitating DFM implementations and improving design specifications in complex aerospace design and manufacturing context.

Similar to PLM approaches, DFM approaches are also a highly product-centric methodology to design, by structuring defect data in a useful manner, useful knowledge can be generated that can be used systematically to carry out DFM implementation by the engineers. Applying DFM approaches can have a pronounced impact on improving product manufacturing when linked and evaluated against any ongoing defects to reduce costs, delivery time and improve quality [9]. Nevertheless, it is not easy to identify useful knowledge based on defect data embedded in various databases across the product lifecycle for carrying out DFM implementations. Researchers are still trying to tackle the "rich data but poor information" problem of PLM systems that many companies still suffer from today [10].

This research addresses the above challenges by carrying out an extensive investigation at BAE Systems (Rochester, UK) that manufactures a mixed portfolio of electromechanical and optical systems for avionic products. The aim of this investigation was to identify how the use of the various accumulated data generated from defects in the products' lifecycle can enable a more systemic DFM implementation strategy using a structured approach. First, an overview of the latest literature in the field was discussed. This was followed by preliminary findings of the industrial issues and research context at the collaborating company from discussions carried out in a series of interviews with function managers (decision makers). An approach for data structuring is proposed that consider the relationships of defects to the engineering data, associated defect information to the engineering data, supply chain issues in defect events, and finally the relationship of the 


\section{A Structured Approach to Defect Data Management for Improving DFM Implementation in Aerospace Manufacturing}

existing defect related databases in PLM system in order to establish a new flow of information, able to be used for carrying out systemic DFM implementations. The main outcomes of this investigation are presented and discussed followed by implications and future work.

\section{Overview of Previous Related Research}

Carrying out DFM implementations is widely recognised in industries as one of the most significant means for reducing manufacturing costs when applied in response to occurring defects and is widely used to maintain product quality including applying knowledge of manufacturing recommendations to the design from lessons previously learned on projects. DFM facilitates improving or controlling the way a part is designed by the means of understanding and applying knowledge of its manufacturability aspects [11]. However, it is critical for today's challenges in manufacturing that the application of DFM methods not only relies on human expert knowledge but also for it to be integrated in the engineering activity using a systemic approach which can be seamless, robust, and responsive to reallife data generated from defects stored in complex PLM systems.

Researchers already recognised that defects that occur in the manufacturing stages of a product are seen in the industry to contribute highly to costs mainly due to what is involved in reworks or scrappages [12]. Defects are disruptive and resource-demanding, and their investigation activities during the manufacturing phase can have various negative impacts on the business such as added costs and late delivery. However, throughout the processes involved in an event of defect, a wealth of data can be captured as a result. This data can be potentially re-used to systemically improve DFM implementations. To this, a high rate of reoccurring defects can be one of the main symptoms of the under-utilisation of DFM methods within a given PLM context.

Additionally, a large proportion of defects can occur on new designs due to their firsttime exposure to unknown manufacturing process capabilities. New capabilities are difficult to predict as the knowledge of manufacturing variability or process parameters, or required improvements come to light after the design's exposure to manufacturing. DFM methods can be used to support product design activities by feeding back knowledge from previous defects to the early design phase of new product development programmes in order to refine engineering controls and mitigate, or evade the design problem, or manufacturing problem that caused previous defects [13].

Likewise, a breakdown in the communication of DFM knowledge can also hinder the implementation of design improvements or DFM implementation. This breakdown can occur due to other reasons - for example, knowledge realised from defects often remain in knowledge 'silos' across manufacturing companies due to not only cultural aspects but also a failure in the effectiveness of data usability, information flow and knowledge feedback cycle. Any kind of knowledge that was realised from defect data may only be effectively used by the engineering teams for implementation if a systemic approach was taken to eliminate any existing failure in the communication between the manufacturing experts and the design engineers when stored and accessed easily from a knowledge repository. It is vital that the industry and researchers of both DFM and KM disciplines recognise the need for structuring defect data that can be used for DFM knowledge creation, as a vital 


\section{A Structured Approach to Defect Data Management for Improving DFM Implementation in Aerospace Manufacturing}

step for pro-active defect reduction measures that can be applied to both new and existing product development programmes.

Furthermore, there have been many researchers that look at how data can be used for knowledge creation and feedback in manufacturing, but often undermine a structured management approach as a key enabler for its success. For example, Goh [14] emphasised the importance of feeding back manufacturing knowledge to improve the design and engineering capability in the aerospace industry, yet the work envisaged an organisational strategy toward improving the knowledge feedback cycle with less emphasis on how organising and structuring data can further enable a higher impact of such strategies. Madenas et al. [15] recognised the benefits of analysing data held at the supplier's knowledge base, and the way to identify and integrate it within PLM systems for the purpose of root cause identification. Chaime [16] recognised the effects of defects on quality management from made (in-house) and supplied parts. Yet, both approaches did not aim to systemically structure the defect data relayed from the suppliers to carry out preventative measures or improved designs by implementing DFM methods early in the product lifecycle (such as in the design stage). Ayishek [17] showed an attempt within the statistical process control capacity to identify root causes of defects by integrating faults in the warranty data from in-service systems to create knowledge of geometric variations in order to improve designs. However, the attempt was specific to the chosen processes and does not provide any framework for organising the defect data that could be used to carry out defect preventative measures such as allowing certain DFM implementations for the given problems.

Other researchers $[18,19,20]$ proposed frameworks to be used for extraction of root causes by analysing quality management data. Similarly, others [21,22] used defect data to carry out analysis for root cause identifications by developing process maps. Although the above papers showed a strong emphasis on individual problem solving, they needed to further explore the potential in their frameworks to identify the relationships between defect data, engineering data, supply chain issues, and the defect causes that can be used for carrying out DFM analysis and how it could prevent future defects.

Within the supply chain management disciplines, previous researchers [23, 24] recognised that potential usable data held in manufacturer's PLM systems are currently too large and unstructured thus disused for improving general efficiencies in manufacturing calling for more work to be done in order for search systems particularly related to product and process variability to be developed and used to aid supply chain decisions. They discussed the use of data that may have been captured for various reasons as potentially valuable when made usable by contextualising it and can also help improved decision making and optimisation for supply chain management when structured in interpretive manners (data to information models). Both proposed models however, do not major on creating the structural links in PLM contexts for using data from within the manufacturing activities that can help improve carrying out design changes or DFM implementations to reduce defects and costs, or improve quality and delivery.

There are some other upcoming research directions that emphasise the importance of human factors in the design of organisational systems that address issues based on 'big data'. For example, Schildt [25] discussed the potential benefits of open-ended big data systems that can include certain types of analysis of text masses to provide new insight (knowledge) from large volumes of data, as opposed to using big data for process 


\section{A Structured Approach to Defect Data Management for Improving DFM Implementation in Aerospace Manufacturing}

optimisation - yet there is still a research need to address how flexible yet focused approach on the design of information systems can enable the creation of knowledge from big data.

All the research papers mentioned in this section, have not delved enough into how the development of a generic framework that can be used to structure data can be achieved, along with an encompassing methodology to integrate and use the approaches in PLM systems in industry for both manufacturing activities carried out in house and components supplied by third parties. In addition, reported research that considered the challenges of addressing big data issues for improving product design in the aerospace industry was found extremely limited and not fully matured in the fields of DFM, KM and PLM.

\section{Industrial Investigation}

\subsection{The Collaborating Company and Research Approach}

BAE Systems (Rochester, UK) produces commercial and defence electronics for flight and engine control, surveillance, communications and geospatial intelligence. The company employs nearly 500 people for their engineering activities and 900 others in operations, supply chain, management, service, maintenance and support. The main product ranges being developed and manufactured in this facility are: heads-up display systems, pilot helmets, pilot control systems, flyby wire systems and integrated flight control systems, all of which are highly sophisticated products that involve complex information management, communications and manufacturing. Although the company manufactures its own novel designs, many of the operations on the assembly line are based on integrating subsystems manufactured by other partners including other BAE Systems facilities, third party suppliers and bespoke manufacturers. A large proportion of these parts are of high value that contain high technological electronics and custom-built components. The Rochester production capacity is up to 20 projects at a time, including assembling, testing, and qualification processes for subsystems to incorporate into larger avionic systems. The volume output of each completed product can be in the region of 10-20 per month which is a very low volume output.

The project was carried out over the past 24 months that gathered real life data at the collaborating company. The types of data gathered included findings from a mixture of observations, interviews and discussions during the investigation. The first part of the investigation reported findings from a preliminary investigation carried out using openended interviews with subject experts at the collaborating company. The second part gathered data based on empirical observations and discussions at the collaborating company and was used to define the research context and build the knowledge needed to elicit the relationships between data management and the different lifecycle stages and processes involved in the aerospace industry. The third part identifies gaps and requirements in industrial practice for addressing big data issues in the given context, and how information management and data structuring being the main focus of the research.

\subsection{Preliminary Investigation}

A preliminary investigation was carried out to identify the current knowledge management challenges at the collaborating company. The interviews included 15 people selected from: technical supply chain, procurement, test systems engineering, quality management, mechanical engineering, project management, business improvements, and manufacturing 


\section{A Structured Approach to Defect Data Management for Improving DFM Implementation in Aerospace Manufacturing}

engineering. The selection criteria for the interviewees was based on the need to gather data from decision makers that had a strong technical background (for at least 10 years) as well as deep knowledge of the types and variety of data captured, how it is currently used and ability to accurately describe its integration within the PLM system used. The interviews consisted of 10 open ended questions lasting between 30-60 minutes each. Findings were manually noted then typed up and represented. Each interview aimed to go through the following issues in detail:

- Current KM challenges for each functioning team,

- Effects of KM challenges on day-to-day activities,

- Overall impact of the challenges on the organisation and

- The required KM solutions to overcome challenges.

Overall, 27 challenges were identified. To this, the challenges were thematically analysed and appropriated in 3 categories, i.e., problem, effect and requirements. From the results of the thematic analysis, the findings have shown that a $47 \%$ of them were direct KM challenges that have underlined a need to improve the management of DFM knowledge. The other $53 \%$ of the KM challenges highlighted issues in the way data is managed in the current manufacturing systems (within PLM system). Detailed recommendations related to organisation issues that were highlighted in the interviews have been reported in more detail in [26]. The findings of the preliminary investigation are discussed below:

\subsubsection{Industrial Issues for Managing DFM Knowledge}

At least 10 interviewees suggested a need to improve the transfer of manufacturing knowledge from the manufacturing phase into the design function and vice versa. At least 8 interviewees highlighted that the defect preventative recommendations on some of the parts assembled in the production cells are difficult to follow up due to production engineer's commitments to production and the design engineer's commitments to engineering. 8 interviewees suggested that the defect data often lacks descriptions that others can use to carry out DFM analysis due to the fact that the data is currently un-structured. Additionally, the current defect reporting process was found to have functional limitations in its ability to quickly identify root causes due to the size of the data produced at each production cell according to all production managers interviewed.

The lessons learnt database had a similar issue as it was found to have a limited capability to trace back and view any details of the defect causes within the datasets according to managers involved in the continuous improvement activities. There is also a shortcoming in the current data management approach for understanding of the impact of defects across the products' lifecycle on quality according to all interviewees. Furthermore, it was clear from the interviewees that multi-disciplinary engineering tasks such as implementing DFM actions into the designs currently relies on face to face communications from the project management team, but would greatly improve if a systemic feedback approach were developed and undertaken. Additionally, it was also clear that expertise knowledge gained from defects falls short on being centralised into a knowledge repository for different design engineers involved in the organisation to carry out DFM implementations. Furthermore, 12 interviewees reported that there is a need for an approach that can systemically align manufacturing process knowledge with the design engineering activities in order to reduce re-occurring defects. At least 4 interviews also suggested that the ability to carry out continuous improvement projects is currently limited due to the lengthy data reviewing 


\section{A Structured Approach to Defect Data Management for Improving DFM Implementation in Aerospace Manufacturing}

process required in each project as projects could run for up to 30 years and knowledge may no longer be fresh in people's minds. This has also emphasised the difficulty from reviewing lessons learned - to align DFM improvements with the process owners and external suppliers.

\subsubsection{Industrial Issues in Data Management}

The interviewees from the production function reported that all manufacturing engineers that support design functions recognise the problem that some of the occurring defects fixed on the production line in the past may re-occur in another period on the same product or other products with similar processes or parts. An example was given of a specific gluing process on components that are required to be fitted without fixtures or fasteners. The example discussed showed that some production engineers have previously resolved this defect by a process improvement approach. Yet upon a re-order of the product, the same defect occurred without first-hand knowledge of any resolution implemented previously. In many cases of similar instances, process experts may be called in to support. This suggests that although DFM solutions may have been implemented previously, the tactical resolution that could potentially eliminate that particular defect amongst the entire organisation is limited due to inaccessibility of any previous knowledge attained from this defect. Moreover, the data related to defects are captured for the purpose of logging, documentation and quality control and lack a feedback feature designed for implementing process control specifications in the engineering data. Similar defects fill up the databases making the list of re-occurring defects extremely long and exhaustive to search through or optimise for a tactical fix across the organisation. This results in putting a big strain on the people in the organisation to communicate knowledge through production meetings and product reviews in order of importance as opposed to a structured systematic approach to be embedded into the current PLM system.

\subsection{Empirical Observations and Discussions}

In addition to the interviews in the preliminary investigation, a second part of the research was carried out as empirical observations of the production line of five complex product assemblies (shown in Table 1) including component manufacture and final system assembly for the duration of the research. This included discussions with the shop floor operators, managers and manufacturing engineers and the resulting contextual findings are reported in Section 3.3.1 to 3.3.6. This is an important part of the research, as it was used to define the research context and discuss the knowledge learned for the duration of this research to elicit the relationships between data management and the different lifecycle stages particular to the aerospace industry.

\begin{tabular}{|c|c|c|c|c|c|}
\hline 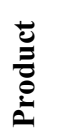 & $\begin{array}{l}\text { Radar Map } \\
\text { Display } \\
\text { System }\end{array}$ & $\begin{array}{l}\text { Head-Up } \\
\text { Display }\end{array}$ & $\begin{array}{l}\text { Helmet- } \\
\text { Mounted } \\
\text { Displays }\end{array}$ & $\begin{array}{l}\text { Primary } \\
\text { Flight } \\
\text { Computer }\end{array}$ & $\begin{array}{l}\text { Inceptor } \\
\text { Systems }\end{array}$ \\
\hline 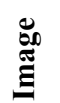 & & & & & \\
\hline
\end{tabular}


A Structured Approach to Defect Data Management for Improving DFM Implementation in Aerospace Manufacturing

\begin{tabular}{|c|c|c|c|c|c|}
\hline 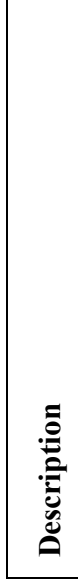 & $\begin{array}{l}\text { Latest } \\
\text { technology } \\
\text { for Radar } \\
\text { processing } \\
\text { graphics and } \\
\text { map } \\
\text { generation } \\
\text { software. }\end{array}$ & $\begin{array}{l}\text { Stable, } \\
\text { accurate, } \\
\text { high integrity } \\
\text { low latency } \\
\text { eyes out } \\
\text { guidance } \\
\text { system. }\end{array}$ & $\begin{array}{l}\text { Provides } \\
\text { flight } \\
\text { reference and } \\
\text { consists of } \\
\text { outer helmet, } \\
\text { inner helmet, } \\
\text { optic visor, } \\
\text { oxygen } \\
\text { mask, night } \\
\text { vision } \\
\text { camera and } \\
\text { head position } \\
\text { tracking } \\
\text { system. }\end{array}$ & $\begin{array}{l}\text { Computes } \\
\text { and transmits } \\
\text { all primary } \\
\text { control } \\
\text { commands to } \\
\text { control and } \\
\text { maintain } \\
\text { flight. }\end{array}$ & $\begin{array}{l}\text { Controls that } \\
\text { pilots use to } \\
\text { direct or } \\
\text { manoeuvre } \\
\text { the aircraft. }\end{array}$ \\
\hline
\end{tabular}

Table 1 The five products, their production line observed and the data collected of defect records to apply the structured approach (Images sourced from BAE Systems' website www.baesystems.com)

\subsubsection{Characteristics of PLM for Aerospace Manufacturing}

Manufacturing in aerospace industry is considered to be of the largest, most complex and resource exhaustive operations. This industry comprises of lengthy production periods, dealing with large number of parts, and is a highly knowledge intensive environment. Unlike many other industries, the aerospace industry also specialises in manufacturing safety critical designs due to the aeronautic operating environment of its products. The core design values in this industry are distinct: extreme robustness, high intricacy, and high efficiency. The five main phases involved for manufacturing in the aerospace sector are: sales stage, the design development stage (also known as engineering), design handover stage, the manufacturing stage (including delivery to customer) and the service and maintenance stage all of which heavily rely on information management based on data held in the PLM system due to the long manufacturing lifecycle involved.

\subsubsection{Scale and Complexity of Data Management in the Engineering Lifecycle}

The initiation of projects once the customers and the business agreed a contract of work, is a complex process and involves a long design development stage before handing the work over to the manufacturing team to produce the designs [27]. The design development process usually involves generating highly complex designs that are safety critical, fail proof, multifunctional, and technological advanced to withstand the aerospace environment they will operate in. The amounts of data generated during this phase is extremely large and discrete to begin with, all of which are governed by a top down approach to PLM at corporate level. In addition, this stage also involves setting up partnerships with the planned suppliers of components to coordinate and establish the required manufacturing controls [28]. These controls are placed within the engineering data to ensure efficient internally or externally controlled assembly line. The controls also aim to guarantee the expected quality management practices, documentation, as well as traceability and visibility [29] within different part of the PLM system. The engineering 


\section{A Structured Approach to Defect Data Management for Improving DFM Implementation in Aerospace Manufacturing}

lifecycle is a sub-management level within the overall PLM system used to contain a broad range of planning activities such as scheduling, configuration, approval processes, and setting up communication channels amongst the teams involved. In order to provide the latest up to date design controls in this stage of the lifecycle, it is important that knowledge of defects faced by the organisation is further considered in the development process, and is made visible for engineers to implement preventative controls into the design data held in the engineering stages in the PLM approach used.

\subsubsection{Challenges in the Design Handover Stage}

At the design to manufacture handover stage, the production team must manage their resources, assembly lines, information flow, and external suppliers to complete the builds on time. This also includes investing in new manufacturing systems, purchasing material, tracking the production outputs, and keeping up with the customer's changing demands. These activities are managed by the Enterprise Resource Planning (ERP) system within the overall PLM approach at the collaborating company. With all these tasks involved in the manufacturing stages, the pressure builds up to deliver finished systems on time. Defects and non-conformity investigations can take up a large proportion of time and, in many cases, can delay deliveries on time. Currently the data captured from defect events is held in multiple stages, and multiple software packages, such as Manufacturing Execution System (MES), that feed into the PLM platform used but not integrated. A structured data management approach can potentially reduce the time taken to complete defect investigations by providing knowledge gained from previous identical defects by integrating and centralising all streams of information from the different defect datasets. It can also improve cause identification by facilitating the causal knowledge feedback cycle.

\subsubsection{Considerations of Data Issues in the Manufacturing Lifecycle}

A typical manufacturing line for a complete product order can last between 10-30 years. Over this lengthy period, defects can occur on a daily basis - the data generated from these defects are captured in various locations within the PLM system (including MES). This depends on where the defects are picked up and how they are dealt with. For example, the defects would be captured in goods-inward, when new material or supplied components are inspected. Other defects would be captured during the assembly stages, the manufacturing stages and the final product testing stage, thus making the management of the data difficult when the data storage, and access points are varied.

In addition, Defects can occur on parts without any upfront knowledge of any root causes previously identified. To avoid any duplicated investigation activities, the latest knowledge of defect causes need to be structured so that links to previously captured investigation outcomes can be provided. Furthermore, the teams involved in the defect investigations learn the root causes of these defects implicitly. This needs to be reflected explicitly on the latest design specifications to make it more effective potentially eliminating repetitive work and helps focus the company's efforts on preventing new types of defects toward an improved zero-defect approach. To have a significant effect on manufacturing efficiency, it is critical for design engineers to have access of knowledge of 


\section{A Structured Approach to Defect Data Management for Improving DFM Implementation in Aerospace Manufacturing}

the latest optimal design specifications required in manufacturing which can only be attained from real-time defect data in order to reduce defects from occurring in the future.

\subsubsection{Lessons Learned in the Product Support and Maintenance Stage}

Several defects related to product use are found when the fully-assembled systems are being tested. The diagnostics for this stage aim to assess and improve reliability in the longer term of the product use by testing the product before shipping it in simulation chambers and compare any data fed back from the system tests to any theoretical calculations specified in the design data. However, the data from this process is generated based on functional failures and can be difficult to link to a root cause in the design or manufacturing of the failed item. Therefore, to help predict the likeliness of failure when the product is in use, the risks associated with any components based on its historic defect data can have a significant impact within this process. Furthermore, any issues documented in lessons learned would also need to fed-back to the design engineers for them to be able to carry out any preventative measures or design improvements using the engineering data. Without the lessons learned link to the engineering data, organisations may struggle to learn from any lessons.

\subsubsection{Supply Chain Issues and Organisational Learning}

The aerospace industry involves a complex supply chain. Many of the assembled items are externally supplied. The designs of some components required from the external specialist suppliers may not currently exist. This often results designs with high risk and manufacturing costs especially when the components have never been made before. It is vital for the design of new products to reflect any previous lessons learned or critical technical factors (including DFM) identified from previous defects to keep the organisational learning effective and produce improved designs. Similarly, it is as vital that any previous defects coming from the supplier's production lines are prevented by making use of the defect data generated from suppliers to embed DFM knowledge into the new design data. In order to achieve this, the understanding of manufacturing capabilities at the supplier's facilities need to be available at hand during the design development. Knowledge of this can be attained by re-using previous defect data to assess particular manufacturing processes and further controlling them. Moreover, the nature of the low volumes of this industry can often result in a lower manufacturing process yield and higher defects from supplied parts due to economic advantages for the supplier. In order to resolve this challenge, imposing preventative measures or additional DFM controls of the critical factors in the design need to be more explicit when outsourcing high value high risk types of designs to keep the process yields high and supplier costs down.

\subsection{Identifying Gap in Industrial Practice}

The third part of this research identifies gaps and requirements in industrial practice for addressing big data issues in the given context, and how information management and data structuring being the main focus of the research based on the empirical investigation findings discussed. To this, the issues discussed been appropriated and represented into a 
A Structured Approach to Defect Data Management for Improving DFM Implementation in Aerospace Manufacturing

single framework that describes the gap in industrial practice and summarises the data required for improving DFM implementation within the PLM system. This can be summarised as below:

Across a large aerospace manufacturing facility, there are several simultaneous projects and live works orders happening at the same time. Many of these projects are continuously faced with defects on some manufactured components or systems. Over a long period of time, the generated defect data, cause investigation data, corrective action data and their knowledge have become widely dispersed, extensively large, and difficult to search and access for the purpose of DFM implementation (see Figure 1). These barriers previously identified and reported in [30] can inhibit the use of the data limiting the ability to prevent future or existing re-occurring defects.

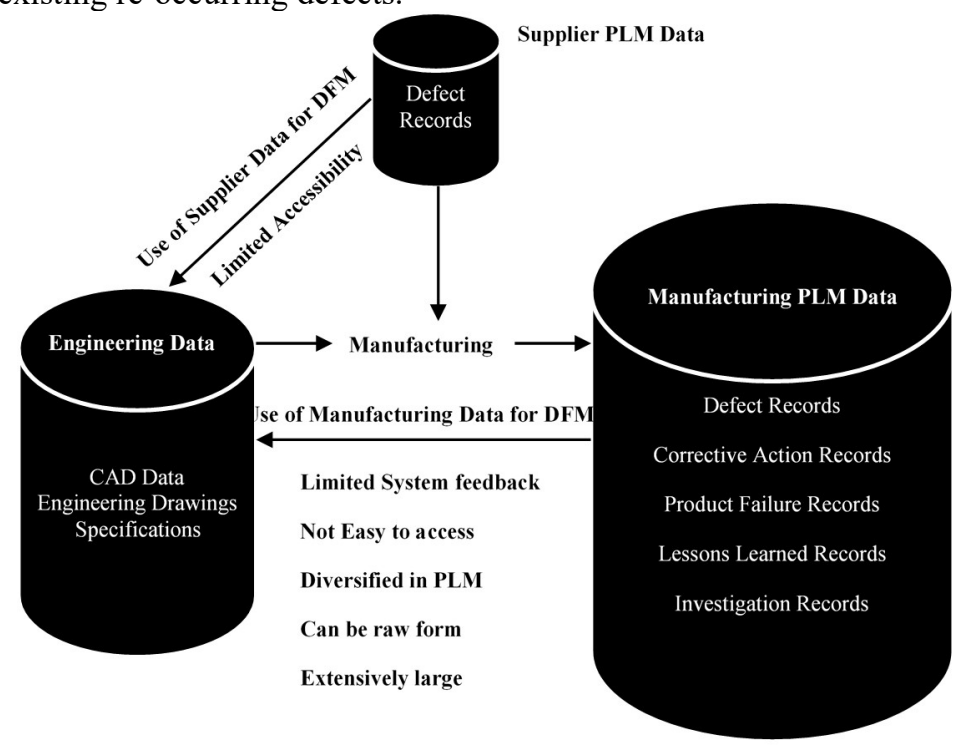

Figure 1 The barriers to Data Management for DFM implementation.

To address this gap, a structured approach to manage the defect data generated in the production line has been proposed. The approach aims to organise the large amounts of dispersed, disconnected defect data generated in the production line and held within different stages of the PLM system and formalise it into modules of data structures to provide connectivity and interpretive context between the defect and the engineering data, the embedded defect related processes, the supply types, and any causal knowledge identified (see Figure 2).

With these linkages enabled within an organised manner for data management, diagnosing new occurring defects can also be cross referenced with previous defects by feeding back knowledge gained from them. Additionally, any new defects can be used to populate the databases with the new structures allocated and this will improve the future process of defect investigations. 


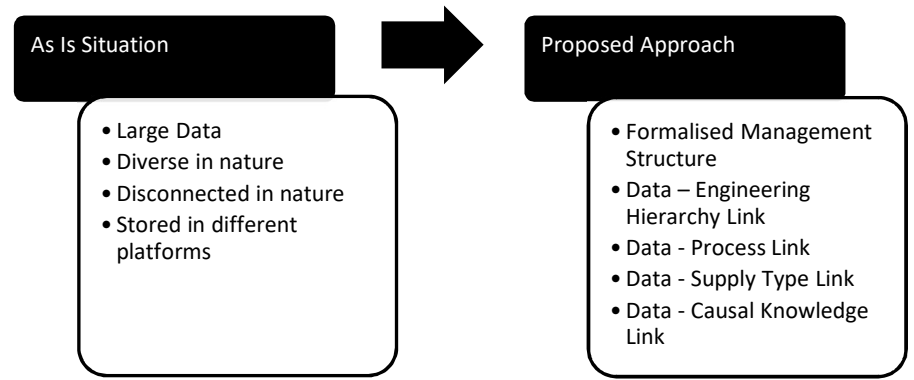

Figure 2 The research approach aimed to manage defect related data by providing organised management structures.

\subsubsection{Identifying the Defect Data within PLM System Context}

In order to develop a structured approach to the defect data and establish the link the part Data, the defect data to be used for the application must be understood in the context of the PLM system. The PLM approach adapted at the collaboration company is based on five stages: Sales, Product Design (Engineering), Design Handover to Manufacturing, Manufacturing, and Service and Maintenance. All of which run a single top-down PLM system where the information flow architecture is integrated within it. However, each of the five stages contains PLM system extension modules that are managed independent of the main PLM software in place.

In the product design (engineering) phase, the product is designed before being handed over to manufacturing. At handover, the Supply Chain management including the procurement plan and product planning for manufacturing is detailed for each of the components, sub-systems, and assemblies, and supplier partnerships are established. In the manufacturing stage, the product is manufactured and assembled for delivering to the customer. The Service and Maintenance stage supports the product (after shipment) when it is in use by the end user customer as well as carries out any final tests ensuring the system's compliance (before shipment) to the customer.

The current data used for capturing and storing the information from defects in the production line consist of 6 separated databases held within 5 types of software systems (using system extension modules). These are: Supply Relationship Management (SRM), MES (Manufacturing Execution System, ERP (Enterprise Resource Planning), Product Lifecycle Management, and Failure Modes and Effects Analysis (FMEA). When a defect occurs on the production lines, two data inputs are carried out by the operator who discovered the defective part. The inputs are captured directly into the quality defect database during the production using MES Software and in the lessons learned database during the function testing using a PLM extension dedicated for lessons learned. The quality defect database is used to record the time, the place, and the symptoms of the defect into a single record. The lessons learned database contains failure related information that has been documented at the project level (or final assembly stage) and it does not require to contain references in its current state of component or sub system information as it is independently managed and is project based. 

Implementation in Aerospace Manufacturing

The quality management function is required to investigate causes of defect, any information accumulated during this process is captured in the investigation database. Any actions taken due to a defect is recorded in the corrective action database. However, any extended investigations are recorded in the quality management database in the ERP Software. Some of the defects are on parts supplied to the production lines from externally managed manufacturing lines (i.e. purchased components) which is held in the supplier's MES software but its communications is managed through SRM Software. This case requires that defect causes are investigated by a third party supplier. The defect related data for this type of situation is not accessible directly but rather through documents saved in the collaborating companies SRM exported there and imported into the ERP software in report format. In addition, in Service and Maintenance stage of the lifecycle, function testing is carried out using complex FMEA software and any new issues found in the design or manufacturability is passed on to the appropriate managers through other forms of communications not currently modelled in the scope of this research as it lacks association to the defect data. All of the above are represented according to the five PLM system stages in Figure 3. The figure shows stored data useful for DFM implementation represented as magnetic disk symbol, activities are represented in rounded rectangle, activities with data access points for inputting defect information are shown in black rounded rectangle.

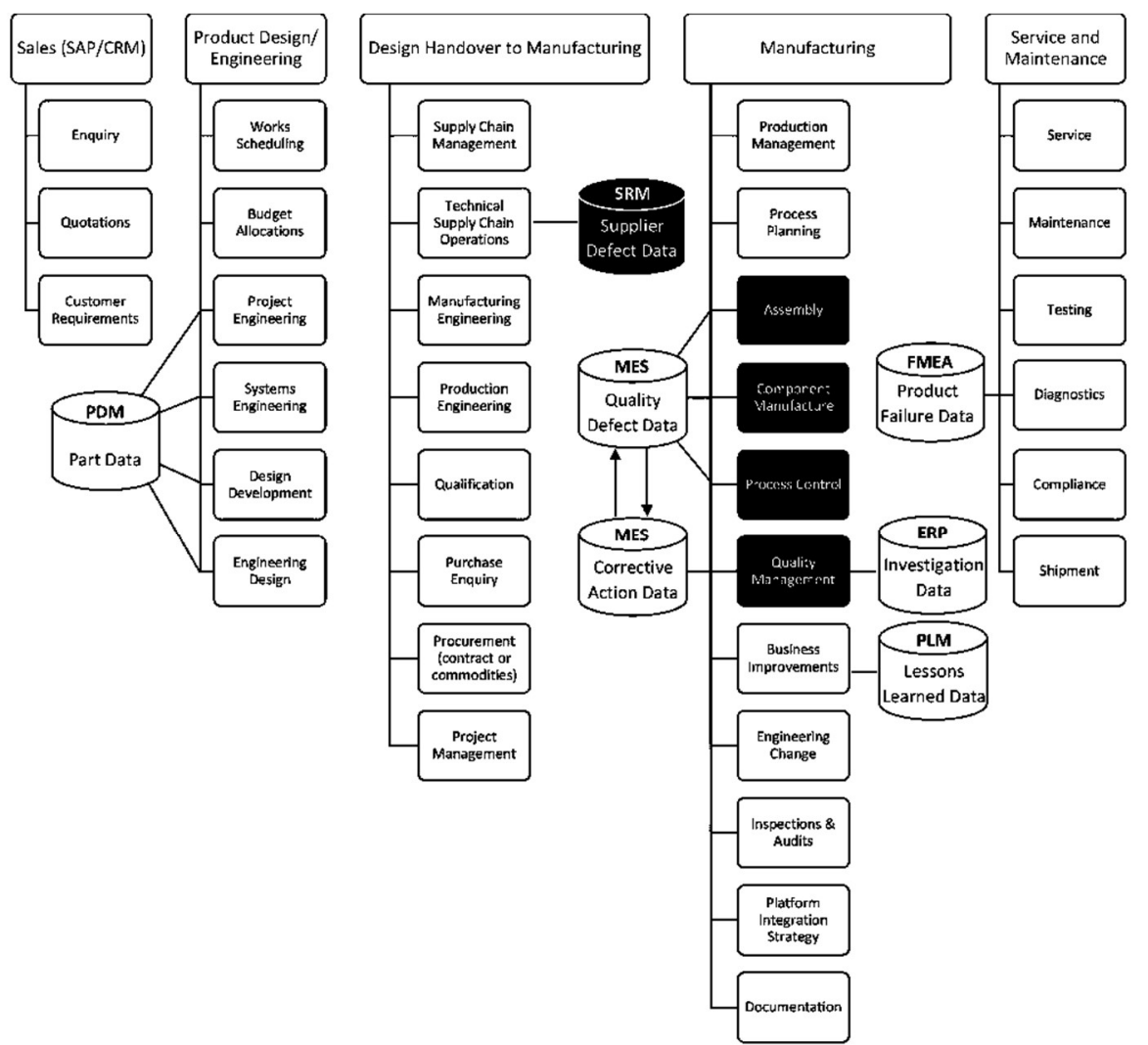

Figure 3 Current defect data stored in relation to the adapted product lifecycle management stages starting from Sales (left) to Service and Maintenance (right) at the collaborating company. 
A Structured Approach to Defect Data Management for Improving DFM Implementation in Aerospace Manufacturing

\subsubsection{Identifying Associated Defect Information and Link to the Part Data}

There are several activities involved in an event of a defect. The typical activity 'pathway' has been modelled and represented in our research to describe the information flows related to each defect (see Figure 4) which will be the basis for associating the information related to a defect in order to incorporate it within the Part Data to be used for DFM implementation .

First when a defect occurred, it is recorded as a defect record, alongside a corrective action if a correction was implemented. The corrective actions contain instructions to rework, scrap, send back, or raise a concession. A record of this information is placed into the corrective action database. Any subsequent investigations done by the quality management team or the technical supply chain team is done independently and recorded in the investigation database. A failure at the final assembly is recorded in the failure database, followed by an overall project review and this data is recorded in lessons learned database. In order to provide the engineering function with a structured view of the processes and data regards a particular defect on a particular part, a need to distinguish between the activities involved on each defect is considered in this model.

For this purpose, the information associated with a defect are proposed by distinguishing the pathways depending on BOM structure of the part we propose to link it to. The organisation of this model has been developed to link the type of defects and each type's pathways in order to retrieve, access and view structured information for the design engineer's use for DFM implementation.

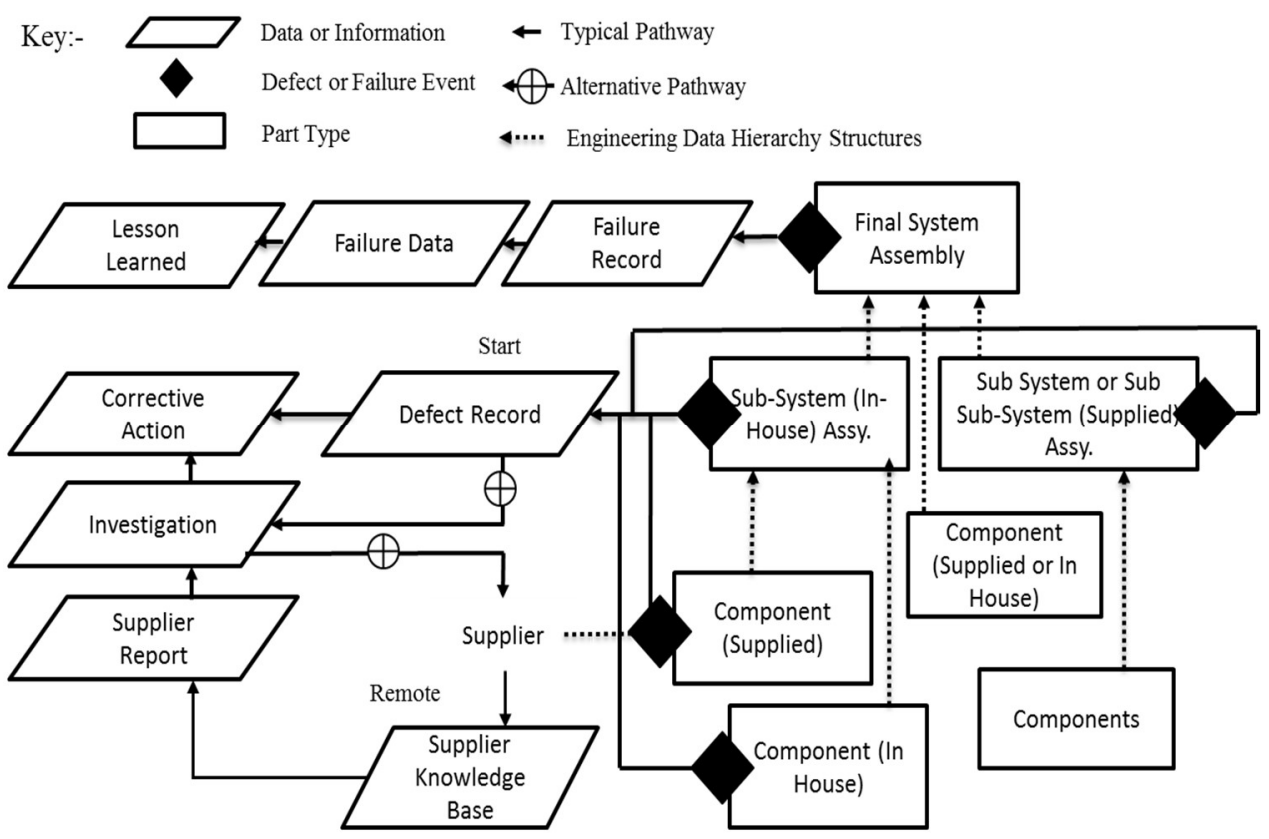

Figure 4 The organisation of the defect activity pathways and related databases and the engineering data link for knowledge feedback. 


\section{A Structured Approach to Defect Data Management for Improving DFM Implementation in Aerospace Manufacturing}

\section{Conclusion and Research Implications}

To conclude, the research carried out a preliminary investigation at the collaborating company identifying the challenges related to managing DFM knowledge and data integration issues to address how defect data can be used to systematically implement DFM. The research also carried out an empirical observation at the collaborating company to identify and discuss the contextual issues related to implementing DFM from defect data within the given PLM context. The research lastly identifies the gap in industrial practice and how information management and data structuring can be used to implement DFM using defect data by identifying the data required from the PLM system to carry out the development as well how the link to the part data is established through the pathway model.

The key factors for the success and foreseen limitations of this research approach are discussed. The current and future research implications are summarised below:

The Quantity and Variety of Data: Although the research proposes identifying the data based on the defect 'pathway' to be represented within the view of the part data, the project requires populating a large size of defect data for testing the model in more detail for each of the components (systems or subsystems) of interest within the organisation. This will provide a critical milestone for our research framework usability across a complete project of multiple components. When the datasets from the five products observed in the industrial investigation have been reviewed, there were over 500 individual data entries into the defect record over a period of 12 months. It is predicted that for each defect record, a factor of 1:5 new data parts will need to be distinguished. The potential quantity of information extraction from associated defect 'pathway' can be well over a factor of 5 per defect record. It is crucial for the development of a scaled up test method to have the ability to quickly and efficiently search the data parts using the approach of our research for providing the required feedback.

Standardisation: A standardised and potentially autonomous approach will be required to analyse defect datasets from different PLM system modules to successfully handle the organisation of large data for DFM feedback for daily use. Additionally, knowledge of root causes identified within each project is virtually hidden amongst historical data and will need to be structured in accordance to the process involved within a pathway.

Accessibility: Supplier caused defects are difficult to manage due to inaccessibility. The need for fully exploiting defects data from external suppliers is critical to overcome any re-occurring defects in the future or amongst other projects using the same supplier or similar designs. Developing this approach requires a partnership programme for addressing IP terms regards their defect data and exposure as well as develop an access point for external data which has not yet been achieved on our project.

Data Integration: The defect data identified within the collaborating company's PLM system uses different software platforms. Many of the databases that store the current defect data uses software integration modules for facilitating data exchange as part of the companies closed loop database architecture policy within PLM software. For example, ERP software is used to manage the operational planning where most of the manufacturing process data is held. On the other hand, MES software platform is used to manage the production activities such as storing symptoms for each defect records. This issue adds to the complexity of linking the defect data - therefore, proposing an integration strategy for 


\section{A Structured Approach to Defect Data Management for Improving DFM Implementation in Aerospace Manufacturing}

the research and industry to use our approach within their own PLM system is critical in future work.

Duplicate Data: Across multiple production lines, a large amount of duplicated defect records can be found due to 'disconnectivety' of data identifiers (some are based on defect, some on project, and some on process). Potentially exploitable knowledge in defect records to improve DFM implementation needs to be synchronised and the duplications reduced by nominating identifiers accordingly.

Knowledge Classification: The knowledge gained by representing the defect data and its associations to allow DFM implementation in the engineering phase needs to be stored for future use. Engineering expertise would still be required to classify any DFM parameters of use - to be implemented to allow others to search for technical design solutions on new defects occurring in production with the same parameters.

\section{$5 \quad$ Contributions and Further Work}

This paper contributes several new aspects of knowledge that is of benefit to the research field as well as industries facing similar challenges of addressing big data issues, and managing manufacturing complexity and its knowledge in general. The paper also provides an understanding of the diversity of data and information systems in an aerospace manufacturing company and addresses the particular challenges associated of linking and integrating these for the purpose of reducing cost, improving quality and delivery (using DFM implementations), which would be of benefit to the company and similar organisations in the business of developing and manufacturing low volume, high value, complex and long-life products. The paper also presented the use of DFM in the context of extended enterprises including the supply chain, particularly by providing a systematic approach to the use of defect data in the given industrial PLM system.

However, not all functionality of the data structured has been fully tested and implemented as a system. Further development work will be undergone in the next stage of the project, and an integration strategy will be developed into the company's PLM system to be effective for business. Furthermore, the project had been presented to stakeholders in the company that included the attendance of chief engineers, management, and directors whom have discussed additional considerations to be implemented in regards to the developed structural data management components to try and incorporate process data which was not fully considered to this date. The project will aim in the next stages of this work to implement a generic data management framework and an IT implementation strategy for the design engineers to be able to use it systematically for carrying out DFM implementations to reduce future defects as well as improve organisational learning and also considering how the knowledge repository required to store DFM implementations can be designed and facilitated through the design of the solution as a system.

\section{Acknowledgements}

This project is funded by the UK Engineering and Physical Science Research Council (ESPRC) Grant: EP/L50544/1 and BAE Systems. The authors would like to thank all the personnel of BAE Systems (Rochester, UK) involved in the investigation for their support and collaboration. 


\section{A Structured Approach to Defect Data Management for Improving DFM Implementation in Aerospace Manufacturing}

\section{References}

[1] Gandhi, P., (2012) 'Product Lifecycle Management Importance and Approach'. International Journal of Applied Information Systems, Vol. 5, No. 6, pp. 28-30

[2] Hans, P., Lomholt, B., and Niels, H. M. (2012), 'Visual Product Architecture Modelling for Structuring Data in a PLM System', In: Product Lifecycle Management, Towards KnowledgeRich Enterprises of the series IFIP Advances in Information and Communication Technology, Vol. 388, pp. 598- 611

[3] Li, J., Tao, F., Cheng, Y., and Zhao, L., (2015), 'Big Data in product lifecycle management', International Journal of Advanced Manufacturing Technology, Vol. 81, pp. 667-684

[4] Spekman, R. \& Davis, E. W. (2016) 'The extended enterprise: a decade later', International Journal of Physical Distribution \& Logistics Management, Vol. 46, No. 1, pp. 43-61

[5] Maksimovic, M., Al-Ashaab, A., Shehab, E., Flores, M., Ewers, P., Haque, B., Furian, R., Lacroix, F. and Sulowski, R. (2014) 'Industrial challenges in managing product development knowledge', Knowledge Based Systems, Vol 71, pp. 101-113

[6] Almada-Lobo, F. (2015) 'The industry 4.0 revolution and the future of manufacturing execution systems (MES)' Journal of innovation management, Vol 3, No. 4, pp. 16-21

[7] Figay, N., Ferreira da Silva, C., Ghodous, P. \& Jardim-Goncalves, R. (2015) 'Resolving Interoperability in Concurrent Engineering'. In: Concurrent Engineering in the 21st Century. s.1.:Springer, pp. 133-163

[8] Poorkiany, M., Johansson, J. and Elgh, F. (2016) 'Capturing, structuring and accessing design rationale in integrated product design and manufacturing processes', Advanced Engineering Informatics, Vol 30, No. 3, pp. 522-536

[9] Nedelcu, B., (2013), 'About Big Data and its challenges and benefits in manufacturing', Database Systems Journal, Vol 4, No. 3, pp. 10-19

[10] Choudhary, A.K., Harding, J.A. and Tiwari, M.K. (2009) 'Data mining in manufacturing: a review based on the kind of knowledge'. Journal of Intelligent Manufacturing, Vol 20, No. 5, pp. 501-521

[11] Huang, G. Q., 'Introduction'. In: Eastman, C.M., ed, (2012), Design for X: Concurrent engineering imperatives. Springer Science \& Business Media, pp. 1-14

[12] Okechukwu, C., E., Uchendu, O., O., Ndubuisi, C., O., and Okpala, C., C., (2015), 'Evaluation of actual costs of rework and scrap in manufacturing industry' Journal of Multidisciplinary Engineering Science and Technology, Vol 2, No. 4, pp. 612-618

[13] Hedberg, Jr, T. D, Hartman, N. W., Rosche, P., and Fischer, K., (2016), 'Identified research directions for using manufacturing knowledge earlier in the product lifecycle', International Journal or Production Research, pp. 1-12 


\section{A Structured Approach to Defect Data Management for Improving DFM Implementation in Aerospace Manufacturing}

[14] Goh, Y., M., and McMahon, C., (2009), 'Improving reuse of in-service information capture and feedback’ Journal of Manufacturing Technology Management, Vol 20, No. 5, pp. 626-639

[15] Madenas, N., Tiwari, A., Turner, C., J., Peachey, S., and Broome, S., (2016) 'Improving root cause analysis through the integration of PLM systems with cross supply chain maintenance data'. International Journal of Advanced Manufacturing Technology, Vol. 84. No. 5. pp. 16791695

[16] Chaime, M., E., (2015) 'Mutual effects of defective components in assemblies', Journal of Manufacturing Systems Vol 36, pp. 1-6

[17] Avishek, P, Franciosa, P., Ceglarek, D., (2014), 'Root Cause Analysis of Product Service Failures in Design -A Closed-loop Lifecycle Modelling Approach', Procedia CIRP 21, pp. 165170

[18] Chooa, A. S., Nagb, R., Xiaa Y., (2015), 'The role of executive problem solving in knowledge accumulation and manufacturing improvements' Journal of Operations Management, Vol. 36 pp. 63-74

[19] Donauer M., Peças, P., and Azevedo, A., (2015), 'Identifying nonconformity root causes using applied knowledge discovery', Robotics and Computer-Integrated Manufacturing, Vol. 36 pp. 84-92

[20] Mourtzisa, D, Doukasa, M., and Skrepetosa, T., (2015) 'A Knowledge-Enriched Problem Solving Methodology for the Design Phase of Manufacturing Equipment' Procedia CIRP 36 in CIRP 25th Design Conference Innovative Product Creation, pp. 95 - 100

[21] Chongwatpol, J., (2015) 'Prognostic analysis of defects in manufacturing', Industrial Management \& Data Systems, Vol. 115, No. 1, pp. 64-87

[22] Ahmad, N., A., Sheran, S., Ahmad, R., and Muhammad, N., (2014), 'Analysis of Product Defects using Failure Mode Effect and Criticality Analysis, A Case Study in Automotive Parts Manufacturing Industry', 8th MUCET 2014, Malaysia, pp. 1-4

[23] Ellran, L. M., and Tate, W., L., (2016), 'The use of secondary data in purchasing and supply management research', Journal of Purchasing \& Supply Management, pp. 1-5

[24] Agrahri, H., Ahmed, F., Verma, V., K., and Purohit, J., K., (2017), 'Benefits of implement big data driven supply chain management: An ISM based model', International Journal of Engineering Science and Computing, pp. 11426-11431

[25] Schildt, H., (2017), 'Big data and organisational design - the brave new world of algorithmic management and computer augmented transparency', Innovation: Organisation \& Management, Vol. 19, No. 1, pp. 23-30.

[26] El Souri, M., Gao, J., Owodunni, O., Simmonds, C., and Martin, N., (2017), 'Improving Design for Manufacturing Implementation in Knowledge Intensive Collaborative Environments - An analysis of organisational factors in aerospace manufacturing', 2017 IEEE Technology and Engineering Management Conference, pp. 448-454 
A Structured Approach to Defect Data Management for Improving DFM Implementation in Aerospace Manufacturing

[27] Periaux, J., Gonzalez, F., and Seop Chris Lee, D., (2015), 'Multidisciplinary Design Optimisation and Robust Design in Aerospace Systems'. In: Evolutionary Optimisation and Game Strategies for Advanced Multidisciplinary Design Vol 75 of the series Intelligent Systems, Control and Automation: Science and Engineering, pp. 53-68

[28] Petersen, K., J., Handfield, R., B., and Ragatz, G. L. (2005) 'Supplier integration into new product development: coordinating product, process and supply chain design'. Journal of Operations Management, Vol. 23, No. 3-4, pp. 371-388

[29] Bindel, A., Rosamond, E., Conway, P., and West, A., (2012), 'Product life cycle information management in the electronics supply chain'. Proceedings of the institution of mechanical engineers part B - Journal of engineering manufacturing, Vol 226, No. 8. pp. 1388-1400

[30] El Souri, M., Gao, J., Owudunni, O., Simmonds, C., and Martin, N., (2016) 'An investigation into the management of design for manufacturing knowledge in an aerospace company'. In: Advances in Manufacturing Technology XXX: Proceedings of the $14^{\text {th }}$ International Conference on Manufacturing Research. Vol. 3, pp. 401-406 